\title{
AN INVESTIGATION OF RECONDITIONING AND DEVELOPMENT OF WEAR AND FRICTION TESTING MACHINE
}

\author{
Nagaraja T.K. ${ }^{1}$, Rathanraj K.J. ${ }^{2}$ \\ ${ }^{1}$ Assistant Professor, Department of Mechanical Engineering, JSSATE Bengaluru, Karnataka, India \\ Email: nagarajajss@rediffmail.com,Phone 9019766429 \\ ${ }^{2}$ Professor and Head, Department of Industrial Engineering \& Management, BMSCE Bengaluru, Karnataka, India
}

\begin{abstract}
The paper objective is to overcome the various problems and shortcomings associated with the present wear and friction testing machine. A new compact track radius attachment is developed, that simplifies the task of adjusting the track radius on to the disc. The various concepts has been generated to develop the track radius mechanism from those it is found that manual operated lead screw concept was most reliable. The product concept was successfully tested and validated by making a physical prototype that yields positive results. The new track radius mechanism setup by itself can be mounted on the guide ways in horizontal position without much physical efforts, demonstrating the flexibility to adjust different track radius feature of the product. The track radius mechanism is offered with flexibility to mount two different specimens in different track radius at a time and tested. The new track radius mechanism has been developed with the additional feature of digital display. The wear and friction testing machine had been reconditioned with all units after rectify the problems of this machine and experiments were conducted to get results on the electronic display. This machine can be used extensively for research applications and precision results can be obtained for industrial applications. The graph is plotted for Aluminum specimen on weight loss with different radial wear track and observed that weight loss increases with an increase in wear track radius.
\end{abstract}

Key Words: wear, pin on disk, wear testing, development, reconditioning. $* * *$

\section{INTRODUCTION}

Wear is mostly a problem and an inevitable cause of any useful engineering process. It is claimed, that wear testing has traditionally been used by material engineers and scientists to rank wear resistance of materials for the purpose of optimizing materials selection or development for a given application. Wear is not a basic material property, but a system response of the material. Wear is generally defined as a progressive loss or displacement of material from a surface as a result of relative motion between that surface and another. Engel [3] describes wear in a similar way. However, Bayer [4] emphasizes, that nowadays material wear is not limited to loss of material. An example would be the change in the geometry or dimension of a part as the result of plastic deformation, such as from repeated hammering, or the development of a network of cracks in a surface.

\subsection{Wear and Friction Testing Methods}

\subsubsection{Pin-On-Disk tribometer}

This continuous rotating Pin-On-Disk Tribometer is one of the most common tribometer to measure the friction coefficient of the tribo-pair during sliding.

\subsubsection{Block-On-Ring tribometer}

Block-on-Ring tribometer is capable of simulating a variety of harsh field conditions, e.g. high temperature, high speed and high loading pressure.

\subsubsection{Plints First Volume Product}

The Company's first volume production tribology test machine was its T E 97 Friction and Wear Test Machine [5]. The design was conceived one afternoon by Dr Michael Plint and Professor Duncan Dowson. Based on a standard Myford lathe, more than two hundred of this simple but effective device were built, with most supplied to universities around the world. For many students in the 1960s, 70s and 80s, the TE 97 will have been their first introduction to tribological testing.

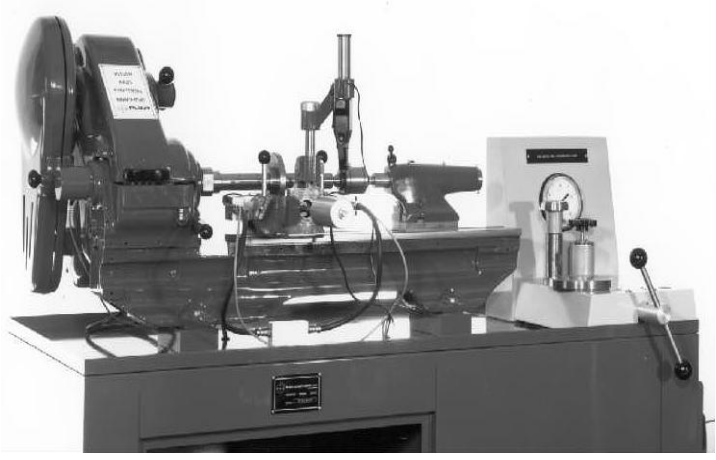

Fig.1 The TE 97 Friction and Wear Test Machine. 


\section{LITERATURE REVIEW}

Etsuo Marui [8] carried out studies from this we can understand practical necessity to obtain the friction and wear characteristics of materials used in machinery, various types of wear-testing machines have been developed and used. To obtain useful data for practical application, it is desirable that the investigation is carried out by a full-scale weartesting apparatus having approximately similar contact conditions. S. Guicciardi [9] carried out research during this ten pin-on-disk sliding wear tests for each experimental condition were carried out with a commercial tungsten carbide (WC) pin on silicon carbide ( $\mathrm{SiC}$ ) disks in order to determine the wear and friction data dispersion. The tests were repeated using two sliding speeds 0.1 and $1.0 \mathrm{~m} / \mathrm{s}$, and two applied loads 5 and $50 \mathrm{~N}$. Khamlichi [10] carried out research in this work, a rational approach based on Taguchi technique and Pin-on-disk test is used in order to study the friction coefficient behavior of clutch facings as function of material formulation. H. Fam [11] studied a method is described by which the coefficient of friction was determined using a linear reciprocating wear testing machine.

\section{PROBLEM DEFINITION}

Based on the literature survey and thoroughly administering the data collected from the above, the problem can be defined as, The present wear and friction testing machine lack the functionality and are associated with various concerns related to track radius, calibration, electronic display etc., This creates a potential opportunity for a new track radius technology which not only overcomes the above concerns but also add some value to the existing product utility.

\section{CONCEPTS}

Development of track radius mechanism can be incorporated in wear and friction testing machine. Hence it is appropriate to develop concepts involving the sliding action. So, four concepts are generated as mentioned in the subsequent sections of this paper.

1. Hydraulic Mechanism

2. Pneumatic Mechanism

3. Manual Lead Screw Mechanism

4. Electric Motor Mechanism

\subsection{Concept 3: Manual lead screw mechanism}

Manual Lead Screw Mechanism in this concept 3, specimen is rigidly fixed with the help of collet, where the collet is fixed inside the block.

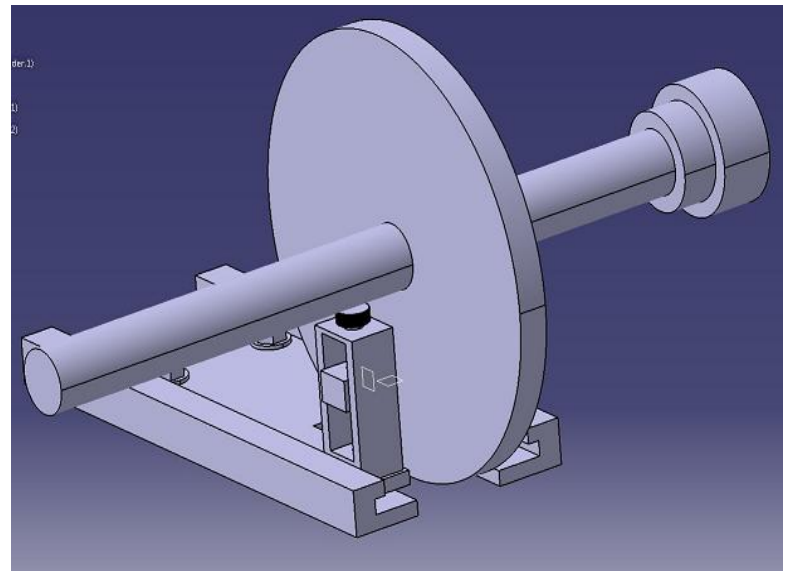

Fig. 2 3-D representation of Manual Lead Screw Mechanism

The block assembly is having the threads mounted on the lead screw which makes the block assembly to have the linear motion when the knob is rotated. The measuring of the track radius with the specimen can be done more accurately. It is flexible to measure the track radius along the disk.

\subsection{Concept selection}

Concept selection is a convergent process of evaluating concepts with respect to the customer needs and other criteria. A two stage concept selection methodology is adopted in this process to select a better concept amongst the concepts generated. The first stage is called Concept Screening and the second stage is called Concept Scoring. The project is further continued for fabrication with concept 3 "Manual Lead Screw mechanism" on the wear and friction testing machine.

\section{FABRICATION OF TRACK RADIUS MECHANISM}

Concept three is materialized and fabricated as shown in fig 3. \& fig 4 with Base plate, Column, Cylinder, Shaft subassembly.
1.Baseplate assembly
2. Column assembly
3. Cylinder assembly
4. Shaft assembly 


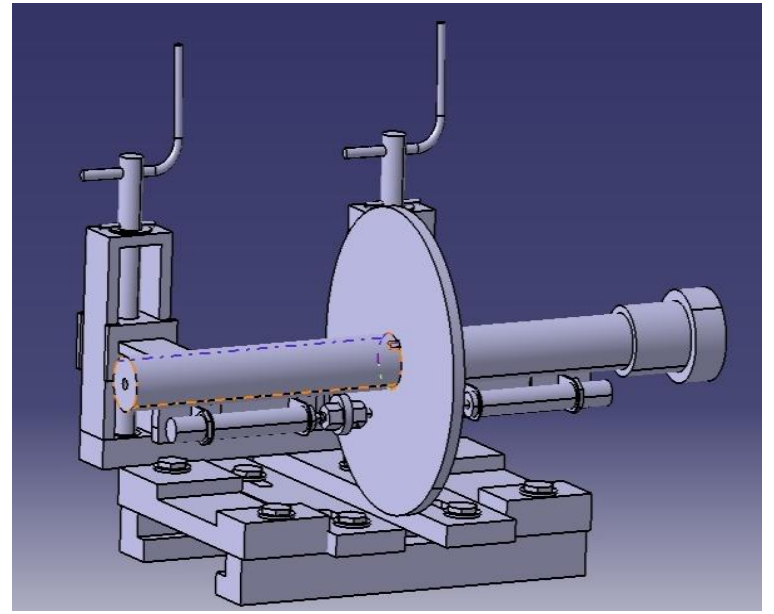

Fig. 3 3-D representation of Track radius Mechanism Assembly.

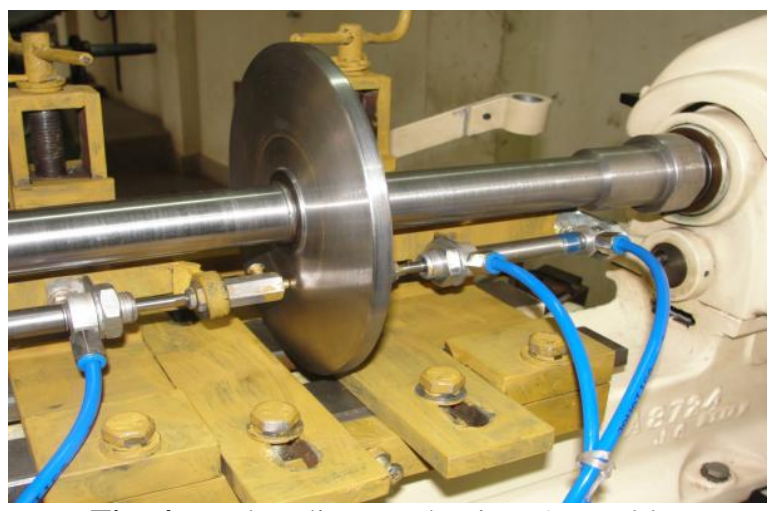

Fig. 4 Track radius Mechanism Assembly.

\section{WORKING OF TRACK RADIUS}

\section{MECHANISM}

The fabricated attachment of track radius mechanism is shown in figure 3 . The track radius mechanism will be working in both retracted and deployed position respectively as shown in fig 4.

\subsection{Working of track radius mechanism in deployed position}

In operation the operator can deploy the track radius by the use of pneumatic cylinders. The pneumatic cylinder is connected to the compressor with the help of pneumatic hose pipe through Filter, Regulator \& Lubricator. The piston of the pneumatic cylinder is fixed with specimen holder where the specimen is located in the specimen holder. When the hand lever valve is operated the specimen is deployed on the friction disc at the predetermined track radius with the help of digital Vernier. The load can be adjusted by turning knob of Filter, Regulator \& Lubricator unit. The shaft is made to rotate at the constant revolutions per minute and the readings are taken at different time intervals. The same process can be repeated for different track radius at different time intervals.

\subsection{Working of track radius mechanism in retracted position}

When the operation of the wear testing at a particular track radius is completed the load can be adjusted to minimum value by turning knob of Filter, Regulator \& Lubricator unit. When the hand lever valve is operated in the opposite direction the specimen along with the specimen holder gets retracted. The shaft is made to stop after taking the readings at different time intervals at the constant revolutions per minute. The specimen taken from the specimen holder is measured for the weight loss. The same process can be repeated for different track radius and different speed at different time intervals.

\section{EXPERIMENTS AND RESULTS}

The experiment is conducted to measure the weight loss for two specimens of Aluminum $8 \mathrm{~mm}$ diameter and Brass of $5 \mathrm{~mm}$ diameter at load of 1 bar and 2 bar pressure respectively. The wear in gram for different time duration at $40 \mathrm{~mm}$ radial wear track and spindle speed of $250 \mathrm{rpm}$ is measured. The two graphs is plotted on the excel sheet representing the right and left specimen with blue and red color respectively which is shown in chart $1 \&$ chart 2 .

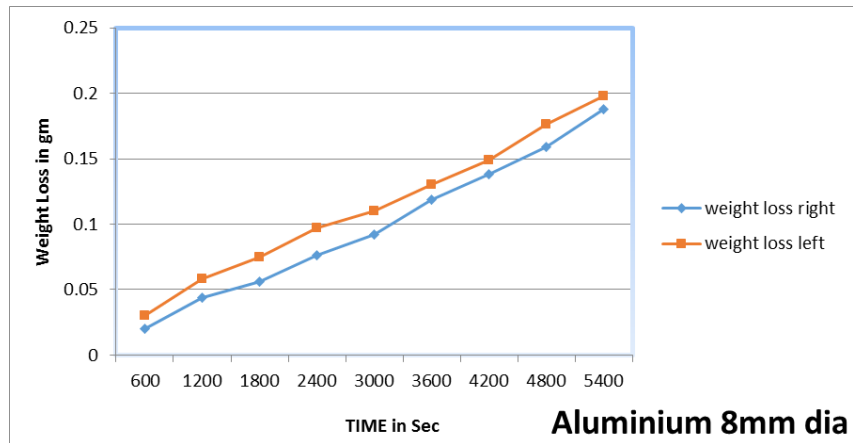

Chart -1 Wear in gram for different time duration at 40mm radial wear track with Aluminum specimen.

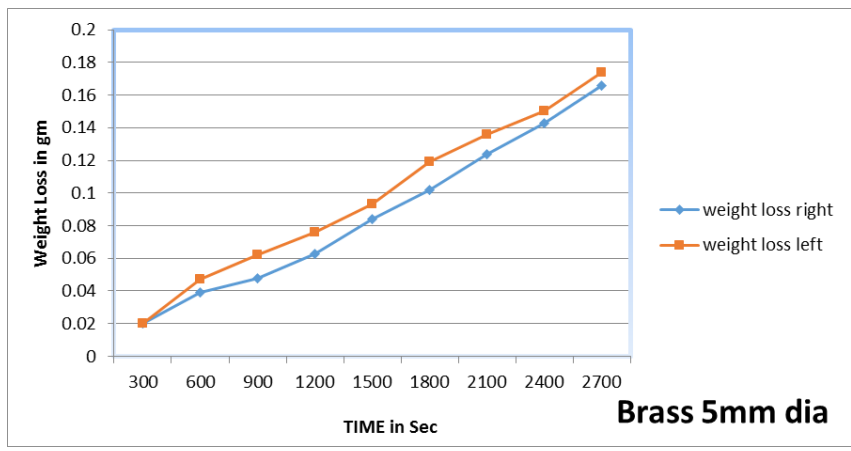

Chart -2 Wear in gram for different time duration at 40mm radial wear track with Brass specimen.

The experiment is also conducted to measure the weight loss for Aluminum specimens of $8 \mathrm{~mm}$ diameter and load of 1 bar pressure. The wear in gram for different time duration at 40 , $45,50 \mathrm{~mm}$ radial wear track and spindle speed of $250 \mathrm{rpm}$ is measured. The two graphs is plotted on the excel sheet representing the right and left specimen with blue, red and 
green color for $40,45,50 \mathrm{~mm}$ radial wear track respectively which is shown in chart $3 \&$ chart 4 .

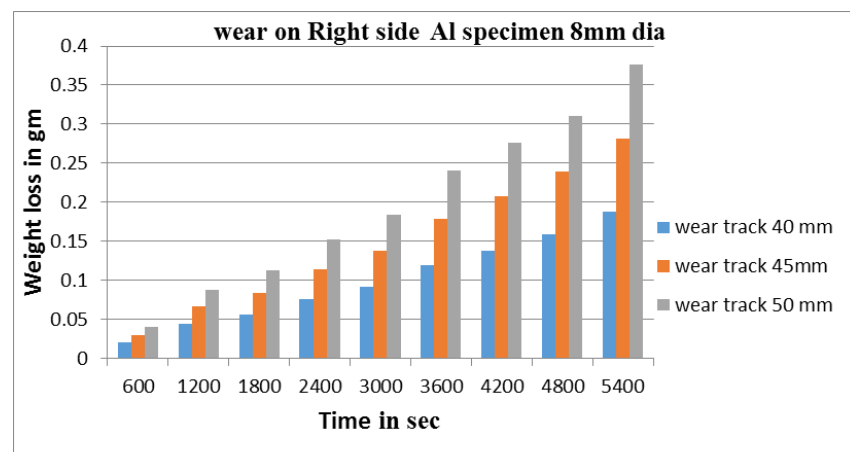

Chart -3 Wear in gram for different time duration at 40, 45, $50 \mathrm{~mm}$ radial wear track with Aluminum specimen at right side.

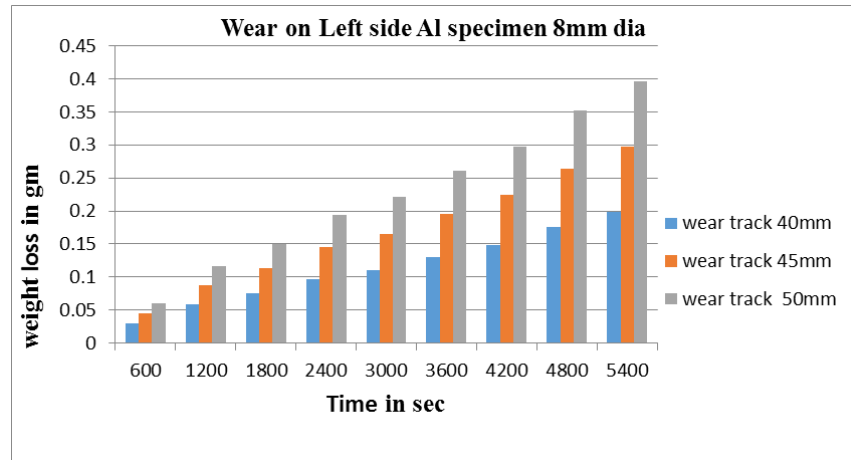

Chart -4 Wear in gram for different time duration at 40, 45, $50 \mathrm{~mm}$ radial wear track with Aluminum specimen at left side.

\section{CONCLUSION}

The problems of Plints wear and friction machine is rectified by doing survey of similar products in the market and reconditioned. The wear and friction testing machine is calibrated with different units like pressure gauge, electronic display and sensors. The machine is also serviced with different systems like mechanical, electrical, electronics and hydraulic system. The wear and friction testing machine was successfully operated with all units working properly. Experiments were also carried out and the results are plotted in the graph.

The development of the Track radius mechanism as an attachment is done by doing survey of similar products in the market. The track radius mechanism works without the aid of any additional power during the operation. The present fabricated track radius mechanism can be operated manually during the change in different track radius. The track radius mechanism ensures complete safety and comfort during the operation. The mechanism fabricated can be operated normally with the digital display of the wear track radius. The graph is plotted for Aluminum specimen on weight loss with different radial wear track and observed that weight loss increases with an increase in wear track radius.

\section{ACKNOWLEDGEMENT}

The authors gratefully acknowledge the support of (a) Department of Mechanical Engineering JSS Academy of Technical Education, Bangalore for the encouragement to carry out the research work (b) Department of Industrial Engineering and Management BMSCE, Bangalore.

\section{REFERENCES}

[1] Ulrich K. T., Eppinger Steven D. (2000), Product Design and Development, Irwin McGraw/Hill

[2] www.tribology-abc.com/abc/history.htm

[3] Reviewshttp:books.google.com/books/about/Impact wear_of_materials.html

[4]Reviewshttp: books.google.co.in/books about Mechanical Wear Fundamentals andTesting.html. CRC Press,

[5] www.phoenix-tribology.com/cat/at2/index/history.pdf

[6] Holm, R Electric Contacts. 1946, H. Gerbers: Stockholm

[7] Archard, J.F., Contact and Rubbing of Flat Surfaces. Journal of Applied Physics, 1953. 24(8): p. 981-988.

[8] http://www.emeraldinsight.com/journals.htm articleid

[9] http://www.ewp.rpi.edu/hartford/ peetrm/MEProject

References/datadispersionPOD.pdf

[10] http://www.academicjournals.org/ijps/pdf/Pdf2008/Feb/ Khamlichiet.pdf

[11]http://tribology.asmedigitalcollection.asme.org/article.as pxarticleid

[12] http://www.sciencedirect.com/science/journal

\section{BIOGRAPHIES}

Mr Nagaraja T.K. obtained his B.E. in Mechanical Engineering from Kuvempu University, Post-Graduation M.Tech from Visvesvaraya Technological University, Belagavi.

Dr. Rathanraj K.J. obtained his B.E. in Mechanical Engineering from Karnataka university, Post-Graduation M.Tech from IIT, Bombay and PhD. from IIT, Bombay. 